\title{
Pengenalan Motif Batik Besurek Menggunakan Teknologi Augmented Reality Berbasis Android \\ ${ }^{1}$ Dwita Deslianti, ${ }^{2}$ Pahrizal \\ ${ }^{1,2}$ Universitas Muhammadiyah Bengkulu, Indonesia \\ Idwitadeslianti@umb.ac.id; 2pahrizaldocik@umb.ac.id;
}

\begin{tabular}{l}
\hline \hline Article Info \\
\hline Article history: \\
Received, 04-06-2021 \\
Revised, 16-06-2021 \\
Accepted, 18-06-2021 \\
\hline Kata Kunci: \\
pascapanen \\
limbah_pertanian \\
pertanian \\
sosialisasi \\
motion_graphic \\
\hline \hline
\end{tabular}

\begin{abstract}
ABSTRAK
Pada umumnya pengetahuan tentang beragam motif batik besurek belum di kenal luas terutama masyarakat Bengkulu, "putri pariwisata Bengkulu, Oktri, di stand Batik besurek arena Expo 2016". Hal ini disebabkan karena belum adanya mediator yang memberikan informasi mengenai batik secara mendetail dan mudah dimengerti. Adapun Informasi saat ini yang didapat hanya berdasarkan gambar, dimana keterbatasan gambar hanya satu dimensi dan informasi didalam gambar masih sangat terbatas. Dari permasalahan tersebut maka penulis akan membahas bagaimana memberikan informasi mengenai Motif Batik Besurek secara mendetail dan mudah dimengerti dengan teknik augmented reality berbasis android. Berdasrkan hasil inisialisasi marker dan hasil uji coba yang dilakukan diukur mengugnakan metode Black Box didapatkan hasil $92 \%$ berhasil untuk mengenali berdasarkan inisialisasi marker yang dilakukan.
\end{abstract}

\section{ABSTRACT}

Keywords:

postharvest agricultural_waste

agricultural

socialization

motion_graphic who provides information about batik in detail and easy to understand. The
In general, knowledge about various batik motifs besurek not widely known, especially the people of Bengkulu, "tourism princess bengkulu, Oktri, in the stand Batik besurek arena Expo 2016". This is because there is no mediator current information obtained is only based on images, where the limitations of the image are only one dimension and the information in the image is still very limited. From the problem, the author will discuss how to provide information about Batik Besurek Motif in detail and easy to understand with augmented reality techniques based on android. Based on the results of marker initialization and the results of the trials conducted measured using the Black Box method obtained a result of $92 \%$ successful to recognize based on the initialization of markers carried out.

This is an open access article under the CC BY-SAlicense.

\section{Penulis Korespondensi:}

Pahrizal,

Program Studi Teknik Informatika,

Universitas Muhammadiyah Bengkulu, Indonesia,

Email : pahrizaldocik@umb.ac.id

\section{PENDAHULUAN}

Di era perkembangan zaman saat ini, batik bukanlah komoditas yang hanya digunakan oleh kalangan tua saja. Batik mulai bergeser menjadi komoditas fashion yang juga digemari oleh remaja. Motif dan mode batik yang berkembang turut mempengaruhi meluasnya pasar batik dewasa ini. Remaja tidak lagi canggung mengenakan batik dan batik tidak lagi dicap kuno salah satunya Batik besurek yang merupakan salah satu warisan budaya dari kota yang dikenal sebagai Gading Cempaka yaitu Bengkulu [1].

Akan tetapi Pada umumnya pengetahuan tentang beragam motif batik besurek belum di kenal luas terutama masyarakat Bengkulu, "putri pariwisata Bengkulu, Oktri, di stand Batik besurek arena Expo 2016". Hal ini disebabkan karena belum adanya mediator yang memberikan informasi mengenai batik secara mendetail dan mudah dimengerti. Adapun Informasi saat ini yang didapat 
hanya berdasarkan gambar, dimana keterbatasan gambar hanya satu dimensi dan informasi didalam gambar masih sangat terbatas.[1]

Dari masalah diatas, penulis merasa perlu untuk mencari solusi agar pengguna dapat dimudahkan dalam mencari informasi tentang batik Besurek. dengan memanfaatkan teknologi saat ini yang berkembang pesat maka diambilah salah satu teknologi yang berkembang dalam hal visual 3D yaitu Augmented Reality[2]. Sehingga pengenalan ragam motif batik besurek menggunakan Media gambar 3D yang disajikan dapat memotivasi masyarakat untuk lebih ingin mengetahui tentang batik Besurek, ditambah lagi dengan informasi batik besurek yang mendetail akan membuat pengetahuan masyarakat tentang ragam motif besurek menjadi bertambah [3].

Augmented reality sebagai penggabungan benda-benda nyata dan maya di lingkungan nyata, berjalan secara interaktif dalam waktu nyata, dan terdapat integrasi antar benda dalam tiga dimensi, yaitu benda maya terintegrasi dalam dunia nyata [2][4]. Dengan memanfaatkan teknologi augmented reality dalam pengembangan aplikasi ini, diharapkan pengguna akan tertarik untuk menggali informasi tentang Batik Besurek. Dengan marker motif Batik Besurek yang telah ditetapkan, pengguna bisa mengaktifkan aplikasi pengenalan motif batik besurek dan mengarahkan kamera ponselnya kearah marker tersebut, maka akan muncul objek 3D motif batik Besurek.

\section{METODE PENELITIAN}

Model Incremental process model merupakan metodologi yang mengkombinasi linier dan iteratif aliran proses dalam pengembangan perangkat lunak. Tujuan utama kombinasi dan iterativ ini adalah mengurangi resiko kegagalan proyek dengan cara memecah pekerjaan menjadi bagian-bagian yang lebih kecil selama pengembangan. Prinsip dasar dalam incremental process model antara lain adalah sebagai berikut [5] [6]:

a. Serangkaian waterfall mini yang harus diselesaikan sebelum melakukan increment berikutnya

b. Semua requirement dilakukan sebelum dilakukan evolusioner

c. Fase-fase dalam setiap increment dilakukan seperti waterfall sehingga diperoleh perangkat lunak yang diinginkan dengan mengikuti fase iteratif seperti pendekatan prototyping [7].

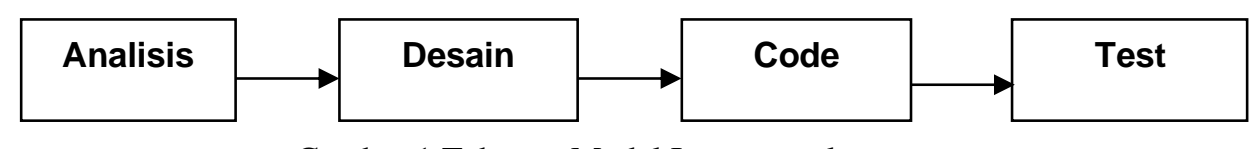

Gambar 1 Tahapan Model Incremental

Dalam penelitian ini akan dilakukan proses segmentasi gambar, adapun alat yang digunakan adalah Teknologi Augmented Reality, sehingga akan menghasilkan aplikasi yang dapat Mengenalkan Motif kain besurek melalui kamera android, dengan cara Menampilkan Motif Batik Besurek dalam Bentuk 3D dan tampak seperti nyata. 


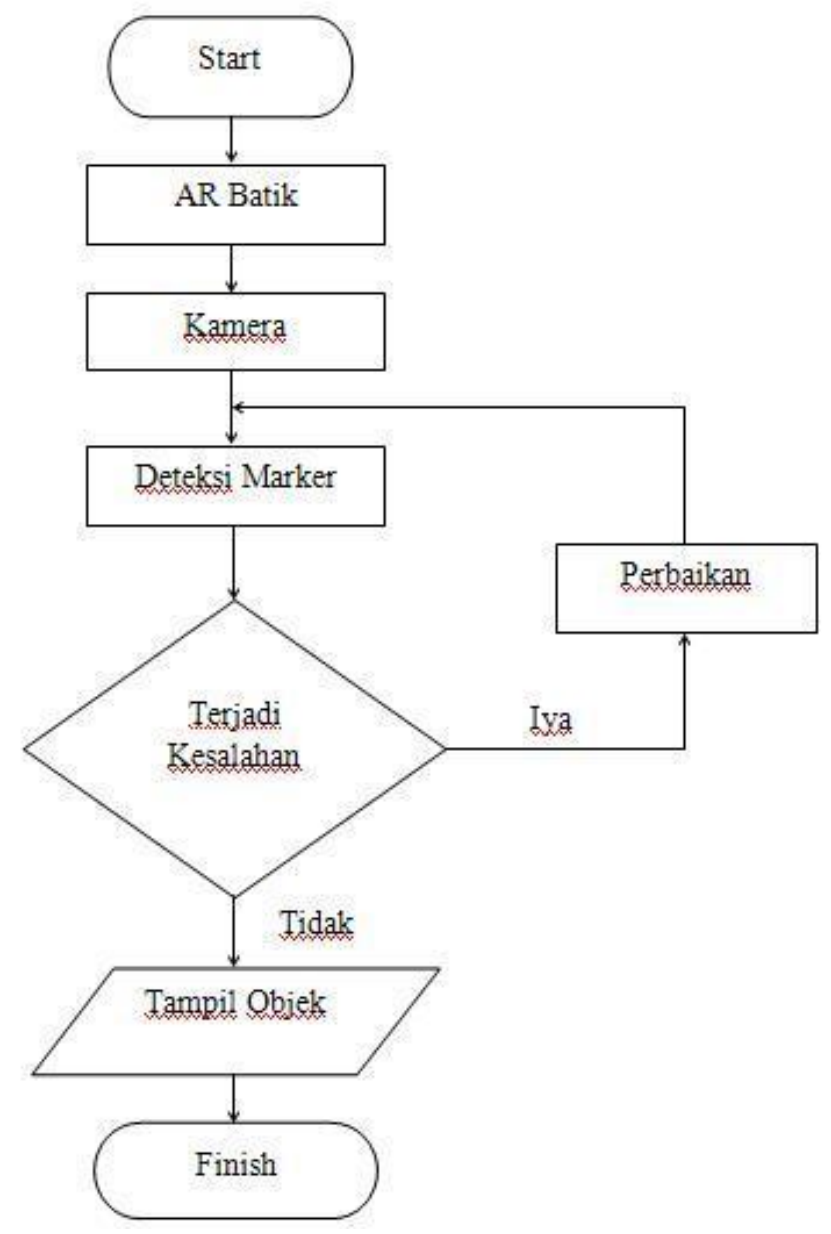

Gambar 2. Flowchart AR Pengenalan Batik Besurek

Metode Pengujian yang digunakan oleh penulis adalah Black Box. "Metode pengujian Black Box testing adalah tipe testing yang memperlakukan perangkat lunak yang tidak diketahui kinerja internalnya. Sehingga para tester memandang perangkat lunak seperti layaknya sebuah "kotak hitam" yang tidak penting dilihat isinya, tapi cukup dikenal proses testing di bagian luar" [8][9].

\section{HASIL DAN ANALISIS}

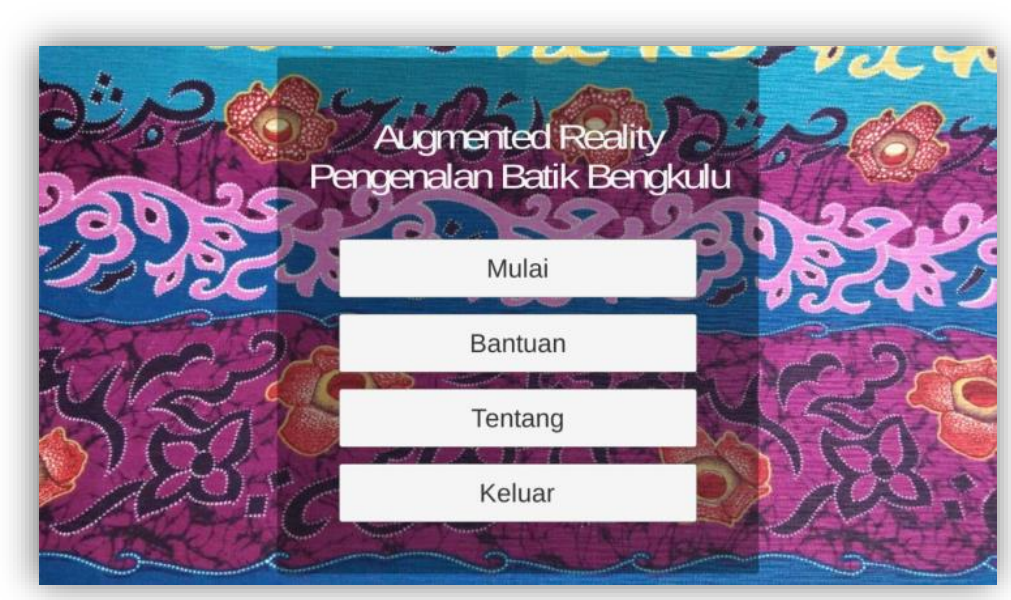

Gambar 3. Menu Utama Aplikasi 
JSAI : Journal Scientific and Applied Informatics

Vol. 4, No. 2, Bulan Tahun, hal. 199 203

E-ISSN: 2614-3054; P-ISSN: 2614-3062, accredited by Kemenristekdikti, Sinta 5

DOI: 10.36085

Menu utama merupakan halaman dimana pengguna dapat berinteraksi dengan aplikasi yang tentunya terdapat beberapa tombol untuk mempermudah penggunaan. Pada halaman utama terdapat tombol, dimana setiap tombol mempunyai fungsi sesuai pilihan atau kata yang terdapat pada tombol. di dalam menu ini terdapat tombol Mulai, Bantuan, tentang dan keluar.

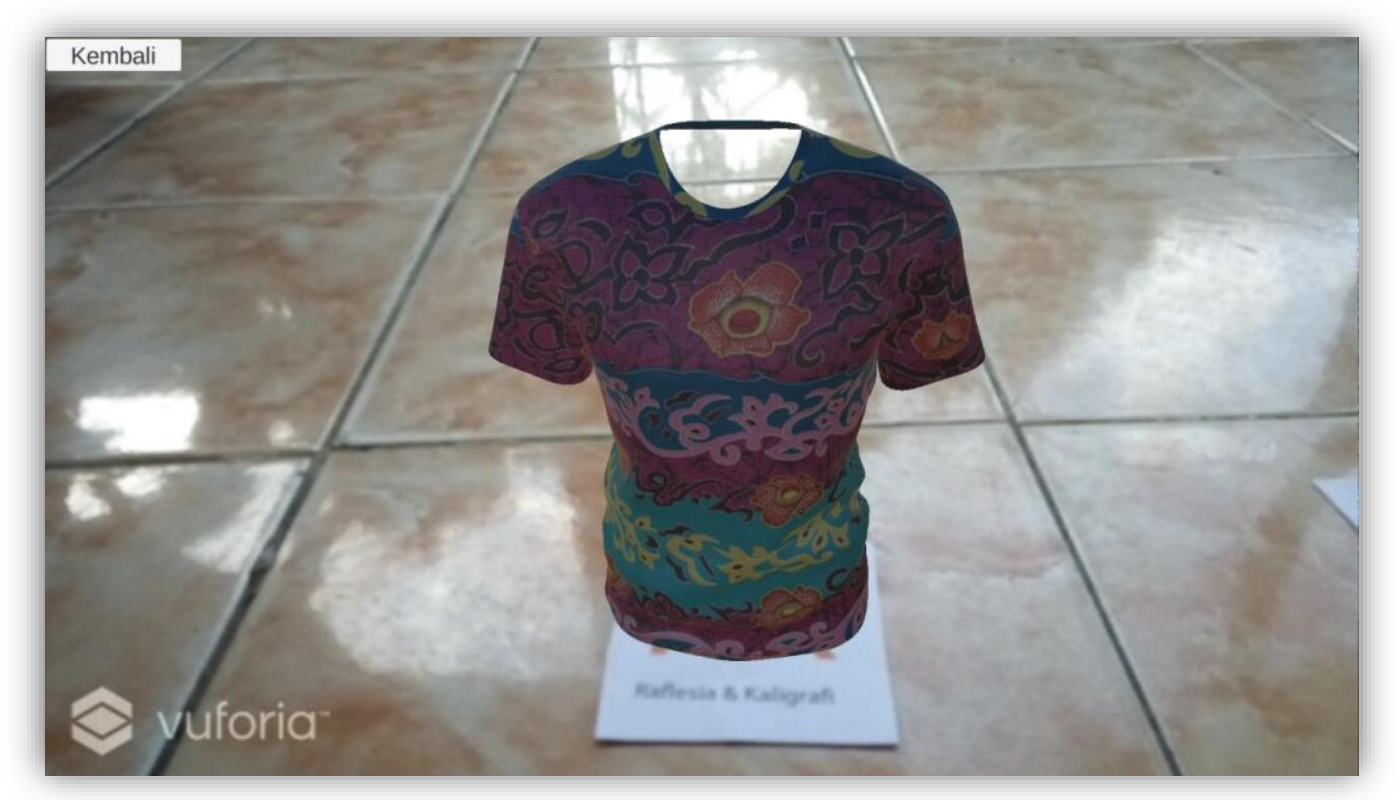

Gambar 4. Hasil Pengenalan Marker

Scan image target pada marker untuk menampilkan objek 3D sesuai dengan gambar marker yang di scan, Ketika kamera berhasil menangkap gambar marker yang sudah didaftarkan pada sistem dan sistem mengenali gambar marker tersebut maka sistem akan memvisualisasikan objek 3D pada posisi diatas gambar marker pada layar kamera. Setiap sisi dari objek 3D dapat dilihat dari berbagai sudut secara real time sesuai dengan sudut pandang kamera.

Berikut adalah pengujian AR pengenalan batik besurek pada tabel 4.1 di bawah ini :

Tabel 4.1 Hasil Pengujian AR Pengenalan Batik Besurek

\begin{tabular}{|c|c|c|c|}
\hline \multicolumn{4}{|c|}{ Kasus Hasil Uji (Data Benar) } \\
\hline Data Masukan & Yang Diharapkan & Pengamatan & Kesimpulan \\
\hline $\begin{array}{lll}\text { Klik } & \text { Menu } & \text { Mulai } \\
\text { AR } & & \end{array}$ & $\begin{array}{l}\text { Dapat menampilkan Menu } \\
\text { Mulai AR }\end{array}$ & $\begin{array}{l}\text { Menu Mulai } \\
\text { berhasil tampil }\end{array}$ & $\begin{array}{l}\text { ( } \sqrt{ }) \text { Diterima } \\
\text { [ ] Ditolak }\end{array}$ \\
\hline $\begin{array}{l}\text { Klik Tombol } \\
\text { kembali }\end{array}$ & $\begin{array}{l}\text { Dapat kembali dari menu } \\
\text { Mulai AR }\end{array}$ & $\begin{array}{l}\text { Berhasil kembali dari } \\
\text { Menu Mulai AR }\end{array}$ & $\begin{array}{l}\text { ( } \sqrt{\text { ) Diterima }} \\
\text { [] Ditolak }\end{array}$ \\
\hline Klik Menu Mulai & $\begin{array}{l}\text { Dapat menampilkan Batik } \\
\text { Burung Kuau }\end{array}$ & berhasil tampil & 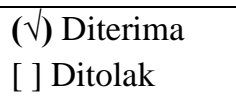 \\
\hline $\begin{array}{l}\text { Klik Tombol } \\
\text { kembali }\end{array}$ & Dapat kembali & $\begin{array}{l}\text { Berhasil kembali ke } \\
\text { menu utama }\end{array}$ & $\begin{array}{l}\text { ( } \sqrt{ }) \text { Diterima } \\
\text { [] Ditolak }\end{array}$ \\
\hline Klik Menu Mulai & $\begin{array}{l}\text { Dapat menampilkan Batik } \\
\text { Daun Bunga }\end{array}$ & berhasil tampil & $\begin{array}{l}\text { ( } \sqrt{ }) \text { Diterima } \\
\text { [ ] Ditolak }\end{array}$ \\
\hline $\begin{array}{ll}\text { Klik } & \text { Tombol } \\
\text { kembali } & \\
\end{array}$ & Dapat kembali & $\begin{array}{l}\text { Berhasil kembali ke } \\
\text { menu Utama }\end{array}$ & $\begin{array}{l}\text { ( } \sqrt{ }) \text { Diterima } \\
\text { [ ] Ditolak }\end{array}$ \\
\hline Klik Menu Mulai & $\begin{array}{l}\text { Dapat menampilkan Batik } \\
\text { Kaligrafi }\end{array}$ & berhasil tampil & 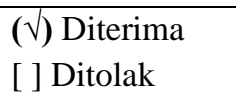 \\
\hline $\begin{array}{ll}\text { Klik } & \text { Tombol } \\
\text { kembali } & \end{array}$ & Dapat kembali & $\begin{array}{l}\text { Berhasil kembali ke } \\
\text { menu Utama }\end{array}$ & $\begin{array}{l}\text { (ل) Diterima } \\
\text { [] Ditolak }\end{array}$ \\
\hline
\end{tabular}


JSAI : Journal Scientific and Applied Informatics

Vol. 4, No. 2, Bulan Tahun, hal. 199 203

E-ISSN: 2614-3054; P-ISSN: 2614-3062, accredited by Kemenristekdikti, Sinta 5 DOI: 10.36085

\begin{tabular}{|c|c|c|c|}
\hline Klik Menu Mulai & $\begin{array}{l}\text { Dapat menampilkan Batik } \\
\text { Melati dan Raflesia }\end{array}$ & berhasil tampil & 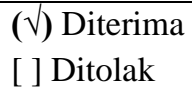 \\
\hline $\begin{array}{ll}\text { Klik } & \text { Tombol } \\
\text { kembali } & \end{array}$ & Dapat kembali & $\begin{array}{l}\text { Berhasil kembali ke } \\
\text { menu Utama }\end{array}$ & $\begin{array}{l}\text { ( } \sqrt{ }) \text { Diterima } \\
\text { [ ] Ditolak }\end{array}$ \\
\hline Klik Menu Mulai & $\begin{array}{l}\text { Dapat menampilkan Batik } \\
\text { Melati dan Relung Paku }\end{array}$ & berhasil tampil & 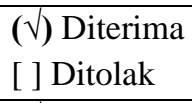 \\
\hline $\begin{array}{ll}\text { Klik } & \text { Tombol } \\
\text { kembali } & \\
\end{array}$ & Dapat kembali & $\begin{array}{l}\text { Berhasil kembali ke } \\
\text { menu Utama }\end{array}$ & $\begin{array}{l}\text { ( } \sqrt{\text { ) D Diterima }} \\
\text { [ ] Ditolak }\end{array}$ \\
\hline Klik Menu Mulai & $\begin{array}{l}\text { Dapat menampilkan Batik } \\
\text { Raflesia dan Kaligrafi }\end{array}$ & berhasil tampil & 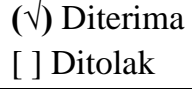 \\
\hline Tombol & Dapat kembali & $\begin{array}{l}\text { Berhasil kembali ke } \\
\text { menu Utama }\end{array}$ & 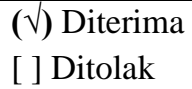 \\
\hline Klik Menu Mulai & $\begin{array}{l}\text { Dapat menampilkan Batik } \\
\text { Relung Paku }\end{array}$ & berhasil tampil & $\begin{array}{l}\text { ( } \sqrt{ }) \text { Diterima } \\
\text { [ ] Ditolak }\end{array}$ \\
\hline $\begin{array}{ll}\text { Klik } & \text { Tombol } \\
\text { kembali } & \end{array}$ & Dapat kembali & $\begin{array}{l}\text { Berhasil kembali ke } \\
\text { menu Utama }\end{array}$ & $\begin{array}{l}\text { ( } \sqrt{ }) \text { Diterima } \\
\text { [] Ditolak }\end{array}$ \\
\hline
\end{tabular}

\section{KESIMPULAN (11 PT)}

Secara umum tujuan peneliti telah dicapai dalam Pembuatan Aplikasi pengenalan motif batik Besurek dengan menerapkan teknologi Augmented Reality pada perangkat Android, Aplikasi ini dapat digunakan dalam dunia pendidikan sebagai alternatif media pembelajaran pengenalan motif kain besurek pada pelajaran seni dan budaya Berdasrkan hasil inisialisasi marker dan hasil uji coba yang dilakukan diukur mengugnakan metode Black Box didapatkan hasil 92\% berhasil untuk mengenali berdasarkan inisialisasi marker yang dilakukan.

\section{REFERENSI}

[1] Y. Brasilka, Ernawati, and D. Andreswari, "klasifikasi citra batik besurek berdasarkan ekstraksi fitur tekstur menggunakan jaringan syaraf tiruan self organizing map (som)," J. Rekursif, vol. 3, no. 2, 2015.

[2] T. A. Ronald, "A Survey Of Augmented Reality, Teleoperator and Virtual Environments," Hughes Res. Lab. Dept Comput. Sci. UNC, 2008.

[3] S. H. Nazruddin, Pemograman Aplikasi Mobile Smartphone dan Tablet PC Berbasis Android. Bandung: Informatika, 2011.

[4] H. Gunawan, "Tingkatan Versi Android," https://haiwiki.info/teknologi/urutan-tingkatan-versisistem-operasi-android/, 2016. .

[5] S. Dharma, "Pendekatan, Jenis dan Metode Penelitian Pendidikan," http://belajarpsikologi.com/pendekatan-jenis-dan-metode-penelitian-pendidikan, 2012. .

[6] S. Rizky, Konsep Dasar Rekayasa Perangkat Lunak. Jakarta: Prestasi Pustaka, 2011.

[7] N. Cholid, Metodelogi Penelitian. 2008.

[8] John, "Metode Pengujian dalam Perangkat Lunak," http://johns 1987.wordpress.com/2013/11/22/3metode-pengujian-dalamperangkat-lunak/, 2013. .

[9] Rahillah, Pengertian Dari Aplikasi. Jakarta, 2013. 